Research Article

\title{
A Study to Assess the Effectiveness of Demonstration Method on Knowledge regarding Neonatal Care among Primi Postnatal Mothers in Selected CHC of Bhopal, Madhya Pradesh
}

\author{
Manjulata Tripathi', MK Rangari' \\ ${ }^{1}$ Principal, ${ }^{2}$ Vice Principal, Corporate College of Nursing, Bhopal, Madhya Pradesh, India. \\ DOI: https://doi.org/10.24321/2348.2141.202103
}

$\begin{array}{lllllll}\mathbf{I} & \mathbf{N} & \mathbf{F} & \mathbf{O}\end{array}$

\begin{abstract}
Corresponding Author:
Manjulata Tripathi, Corporate College of Nursing, Bhopal, Madhya Pradesh, India.

E-mail Id:

manrajtripathi@gmail.com

Orcid Id:

https://orcid.org/0000-0002-2741-8517

How to cite this article:

Tripathi M, Rangari MK. A Study to Assess the Effectiveness of Demonstration Method on Knowledge regarding Neonatal Care among Primi Postnatal Mothers in Selected CHC of Bhopal, Madhya Pradesh. Trends Nurs Adm Edu. 2021; 10(1):14-16.
\end{abstract}

Date of Submission: 2021-05-29

Date of Acceptance: 2021-06-21

\section{$\begin{array}{llllllll}\mathbf{A} & \mathbf{B} & \mathbf{S} & \mathbf{T} & \mathbf{R} & \mathbf{A} & \mathbf{C} & \mathbf{T}\end{array}$}

Background: This study was conducted to assess the effectiveness of demonstration method on knowledge regarding neonatal care among primi postnatal mothers.

Method: An experimental research approach was used to determine the effectiveness of demonstration method on the level of knowledge regarding neonatal care among primi postnatal mothers in selected CHC, Bhopal, Madhya Pradesh. The sample consisted of 60 primi postnatal mothers who met the sampling criteria. The participants were interviewed using structured questionnaires with multiple items including socio-demographic profile, parity, and gestational age at initial antenatal care, knowledge regarding neonatal care, thermoregulation, eye care, and skin care. A pre and post-test were used to assess their knowledge regarding neonatal care.

Result: The pre-test showed that most of the respondents (42 (70\%)) had inadequate knowledge, $13(21.66 \%)$ respondents had moderate knowledge, and only 5 (8.33\%) mothers had adequate knowledge. After educational intervention, the level of knowledge of mothers increased, i.e. about $36(60 \%)$ respondents gained adequate knowledge regarding neonatal care while $16(26.66 \%)$ acquired a moderate level of knowledge.

Conclusion: The study proved that demonstration method can be useful to primi postnatal mothers for increasing their knowledge regarding neonatal care.

Keywords: Neonatal, Post Natal, CHC, Demonstration, Thermoregulation

\section{Introduction}

Infant mortality rates are still high in India, as compared to developed countries. One million neonates die per annum in our country. Neonatal deaths account for $63.7 \%$ of all infant deaths in India. Our country accounts for $27 \%$ of the global burden of neonatal deaths each year. ${ }^{1}$ It is recognised that to reduce infant mortality rate, majority of health problems that occur during the first month of life should be dealt with on a priority basis. Most of the infant 
mortality occurs due to severe infections which account for $36 \%$ of all deaths and is mostly caused due to sepsis, pneumonia, and tetanus and diarrhoea accounting for $26 \%$, $7 \%$, and $3 \%$ of the deaths respectively. ${ }^{2}$

The health of the future citizens of a nation depends on the care which we are providing to our children today. The health of children depends on the nurturing practices adopted by the mothers. ${ }^{3}$ Primi postnatal mothers have poor knowledge of essential care of newborn babies, especially the mothers belonging to remote village areas. To reduce infant mortality rate, it is very important to create awareness regarding the care of neonates, especially umbilical care, thermoregulation, eye care and feeding among primi postnatal mothers. ${ }^{4}$

\section{Statement of the Problem}

A study to assess the effectiveness of demonstration method on knowledge regarding neonatal care among primi postnatal mothers in selected $\mathrm{CHC}$ of Bhopal, Madhya Pradesh.

\section{Objectives of the Study}

To assess the knowledge on neonatal care among primi postnatal mothers.

To assess the effectiveness of demonstration methods on knowledge among primi postnatal mothers.

\section{Hypothesis}

H1: There will be statistically significant difference between pre-test and post test knowledge score regarding neonatal care among primi post natal mothers.

\section{Methodology}

Research Approach: An experimental research approach was used to determine the effectiveness of demonstration method on the level of knowledge regarding neonatal care among primi postnatal mothers in selected $\mathrm{CHC}$ of Bhopal, Madhya Pradesh.

Research Design: Experimental one group pre-test posttest design was adopted for the study.

Setting of the Study: The study was conducted in selected $\mathrm{CHC}$ of Bhopal, Madhya Pradesh.

Sample: The sample consisted of 60 primi postnatal mothers who met the sampling criteria.

Sampling Technique: The sample was selected using the convenient sampling method.

\section{Criteria for Selection of Sample}

\section{Inclusion Criteria}

The study included primi postnatal mothers who were accessible during the study and those who were actively willing to participate in it.

\section{Exclusion Criteria}

Multigravida mothers, mothers whose postnatal duration exceeded five days, and who had already attended the class on neonatal care were excluded from the study.

\section{Ethical Clearance}

Permission was taken from the concerned authority in Community Health Centre, Bhopal, Madhya Pradesh. Informed consent from the participants was obtained. Confidentiality and privacy of data were maintained.

Tool: A self-structured questionnaire was developed by the investigators based on the research problem to collect the data. The tools consisted of two sections:

Section A: It dealt with the Demographic Performa which consisted of ten items such as age, area of residence, type of delivery, gestational weeks, area of residency etc.

Section B: It consisted of multiple-choice knowledge questionnaires regarding knowledge on neonatal care among primi postnatal mothers.

\section{Data Collection Procedure}

The participants were interviewed using structured questionnaires with multiple items, including sociodemographic profile, parity, and gestational age at initial antenatal care, knowledge regarding neonatal care, thermoregulation, eye care, and skin care.

\section{Score Interpretation}

The interpretation of score was done according to the knowledge of primi postnatal mothers regarding neonatal care. The knowledge of the mothers was classified as adequate, moderate, and inadequate knowledge. A score higher than $75 \%$ was categorised as adequate knowledge while less than $50 \%$ was categorised as inadequate knowledge (Table 1). Mothers with adequate knowledge needed only instructions about neonatal care and those with inadequate knowledge required educational intervention through demonstration method.

Table I.Score Interpretation

\begin{tabular}{|c|c|}
\hline Criteria & Score \\
\hline Adequate knowledge & $>75 \%(21-30)$ \\
\hline Moderate knowledge & $51-75 \%(11-20)$ \\
\hline Inadequate knowledge & $<50 \%(1-10)$ \\
\hline
\end{tabular}

Result The pre- and post-test of primi postnatal mothers regarding their knowledge of neonatal care revealed that most of the respondents $(42$ (70\%) had inadequate knowledge in pre-test, $13(21.66 \%)$ respondents had moderate knowledge and only 5 (8.33\%) mothers had adequate knowledge. After educational intervention, 
the knowledge level of mothers had increased, i.e. about $36(60 \%)$ respondents had gained adequate knowledge regarding neonatal care while $16(26.66 \%)$ had acquired a moderate level of knowledge (Table 2 ). the effectiveness of demonstration methods on knowledge regarding neonatal care among primi postnatal mothers in selected $\mathrm{CHC}$, Bhopal, Madhya Pradesh. This study proves the efficacy of demonstration methods since a significant

Table 2.Pre-test and Post-test Knowledge Scores

\begin{tabular}{|c|c|c|c|c|c|c|}
\hline \multirow{2}{*}{ Variables } & \multicolumn{2}{|c|}{ Inadequate Knowledge } & \multicolumn{2}{c|}{$\mathrm{n}=60$} \\
\cline { 2 - 7 } & Frequency & Percentage & Frequency & Percentage & Frequency & Percentage \\
\hline $\begin{array}{c}\text { Pre-test Knowledge } \\
\text { Score }\end{array}$ & 42 & 70 & 13 & 21.66 & 5 & 8.33 \\
\hline $\begin{array}{c}\text { Post-test Knowledge } \\
\text { Score }\end{array}$ & 8 & 13.33 & 16 & 26.66 & 36 & 60 \\
\hline
\end{tabular}

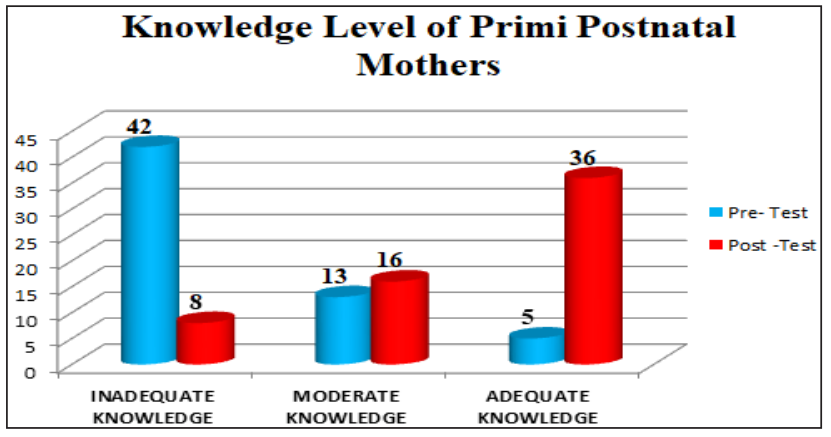

Figure I.Pre-test and Post-test Knowledge Levels of

Primi Postnatal Mothers on Neonatal Care

Table 2 and Figure 1 clearly show that there was a significant difference between the pre-test and post-test knowledge scores regarding neonatal care among the respondents, hence our previous hypothesis has been accepted.

\section{Discussion}

\section{Knowledge on Neonatal Care among Primi Postnatal Mothers}

A pre-test questionnaire was provided to the participants through interviews to assess their knowledge regarding neonatal care. It was found that most of the respondents (70\%) had inadequate knowledge regarding proper neonatal care. $^{2}$

\section{Effectiveness of Demonstration Methods on Knowledge of Primi Postnatal Mothers}

An educational intervention regarding information on neonatal care was provided to the respondents through demonstration methods. A post-test was conducted to assess their knowledge after the intervention. The result obtained revealed that about $60 \%$ of the respondents had adequate knowledge about neonatal care. ${ }^{3}$ This increase in knowledge among the participants clearly proves the efficiency of demonstration methods.

\section{Conclusion}

The study was conducted with the objective to evaluate increase in knowledge of the primi postnatal mothers was seen after the intervention. Neonatal care is of extreme importance and is still an area in which mothers are not very well-versed. Therefore, this study can be used as a basis for employing demonstration methods in order to provide knowledge to the mothers, to ensure proper health of the newborns.

\section{Source of Funding: Self \\ Conflict of Interest: None \\ References}

1. Zupan J. Perinatal mortality in developing countries. New Engl J Med. 2005;352(20):2047-48. [PubMed] [Google Scholar]

2. Senarath U, Fernando DN, Vimpani G, Rodrigo I. Factors associated with maternal knowledge of newborn care among hospital delivered mothers in Sri Lanka. Trans $\mathrm{R}$ Soc Trop Med Hyg. 2007 Aug;101(8):823-30. [PubMed] [Google Scholar]

3. Baqui AH, Williams EK, Darmstadt GL, Kumar V, Kiran TU, Panwar D, Sharma RK, Ahmed S, Sreevasta V, Ahuja R, Santosham M, Black RE. Newborn care in rural Uttar Pradesh. Indian J Pediatr. 2007;74(3):241-7. [PubMed] [Google Scholar]

4. Obimbo E, Musoke RN, Were F. Knowledge, attitudes and practices of mothers and knowledge of health workers regarding care of the newborn umbilical cord. East Afr Med J. 1999 Aug;76(8):425-29. [PubMed] [Google Scholar]

5. Rahman M, Islam MA, Mahalanabis D. Mother's knowledge about vaccine preventable diseases and immunization coverage of a population with high rate of illiteracy. J Trop Pediatr. 1995;41(6):376-78. [PubMed] [Google Scholar]

6. Das DK, Ahmed S. Knowledge and attitude of the Bangladeshi rural mothers regarding breastfeeding and weaning. Indian J Pediatr. 1995;62(2):213-17. [PubMed] [Google Scholar] 